\title{
Luminescence Line Broadening of CdSe Nanoplatelets and Quantum Dots for Application in w-LEDs
}

Johanna C. van der Bok, Daphne M. Dekker, Matt L.J. Peerlings, Bastiaan B.V. Salzmann and Andries Meijerink*,

Debye Institute of Nanomaterial Science, Utrecht University, The Netherlands.

Corresponding author*: a.meijerink@uu.nl

\section{Chemicals}

1-butanol (anhydrous, 99.8\%), 1-octadecene (ODE, 90\%), 1-octanethiol (98.5\%), 2-propanol (99.5\%), cadmium acetate dihydrate (98\%), cadmium nitrate tetrahydrate $(99,99 \%$, trace metal basis), hexane (anhydrous, 95\%), methanol (anhydrous, 99,8\%), N-methylformamide (NMF, 99.8\%), octadecylamine (ODA, 90\%), oleic acid (OA, 90\%), oleylamine (70\%), sodium hydrosulfide hydrate, Sodium myristate ( $\geq 99 \%)$, Sulfur (S, 99.998\%), trioctylphosphine (90\%), toluene (anhydrous, 95\%), triethylamine ( $\geq 99 \%)$, trifluoroacetic acid (99\%), trifluoroacetic anhydride (99\%), trioctylphosphine oxide (90\%) were all purchased from Sigma Aldrich. Sodium acetate $199.999 \%$ pure on trace metal basis) was purchased from Merck. Selenium powder (200 mesh, 99.999\%) was purchased from Brunschwig Chemie.

\section{Synthesis CdSe QDs and CdSe/CdS core-shell QDs based on Li et al. ${ }^{1}$ Precursors}

A $0.065 \mathrm{M}$ cadmium oleate precursor was prepared by degassing a mixture of $0.64 \mathrm{~g}$ cadmium acetate dihydrate, $25.9 \mathrm{~g}$ 1-octadecene (ODE) and $3.73 \mathrm{~g}$ oleic acid (OA) for 2 hours at $120^{\circ} \mathrm{C}$ under vacuum. A $0.74 \mathrm{M}$ TOP-Se solution was made by dissolving $1.4 \mathrm{~g}$ elemental selenium in $7.5 \mathrm{~g}$ trioctylphosphine at $80^{\circ} \mathrm{C}$. After the selenium was dissolved $11.9 \mathrm{~g}$ ODE was added.

For the shell growth a $0.1 \mathrm{M}$ cadmium precursor was prepared by degassing $1.07 \mathrm{~g}$ cadmium acetate dihydrate, $23.6 \mathrm{~g} \mathrm{ODE}$, and $9.05 \mathrm{~g} \mathrm{OA}$ at $120^{\circ} \mathrm{C}$ under vacuum for 2 hours. To obtain a $0.1 \mathrm{M}$ sulfur precursor, $48 \mathrm{mg}$ elemental sulfur was dissolved in $11.8 \mathrm{~g}$ ODE at $180^{\circ} \mathrm{C}$

\section{Synthesis of CdSe QDs}

A mixture of $1.11 \mathrm{~g}$ trioctylphosphine oxide (TOPO), 3.2 gram octadecylamine (ODA) and $5.2 \mathrm{~g}$ TOPSe precursor was heated to $300^{\circ} \mathrm{C}$. $4.9 \mathrm{~g}$ of the $0.065 \mathrm{M}$ cadmium precursor was rapidly injected. After the injection the temperature was kept at $280-290^{\circ} \mathrm{C}$. QDs of different sizes were made by varying the reaction time from seconds up to 10 minutes. Particles were purified twice with 1 equivalent toluene, 1 equivalent methanol and 2 equivalent butanol and centrifuged at $2500 \mathrm{rpm}$ (700 RCF) for $10 \mathrm{~min}$. The QDs were dispersed in $10 \mathrm{~mL}$ toluene.

\section{Synthesis CdSe/CdS core-shell QDs}

$0.820 \mathrm{~mL}$ of a $0.122 \mathrm{mM} \mathrm{CdSe}$ QD solution in toluene (diameter particle: $3.6 \mathrm{~nm}$ ), 1 gram ODA and 3 $\mathrm{mL}$ ODE was heated to $150^{\circ} \mathrm{C}$. After all toluene was evaporated the mixture was heated to $240^{\circ} \mathrm{C}$. Alternately a $0.1 \mathrm{M}$ cadmium precursor or a $0.1 \mathrm{M}$ sulfur precursor was added dropwise with intervals of $10 \mathrm{~min}$. For the first and second CdS layer $0.180 \mathrm{~mL}$ and $0.225 \mathrm{~mL}$ of the precursor solutions was added respectively. Core-shell particles were purified as described above.

Transmission electron microscopy (TEM) images of core QDs of different sizes and core-shell QDs are shown in figure S1. 

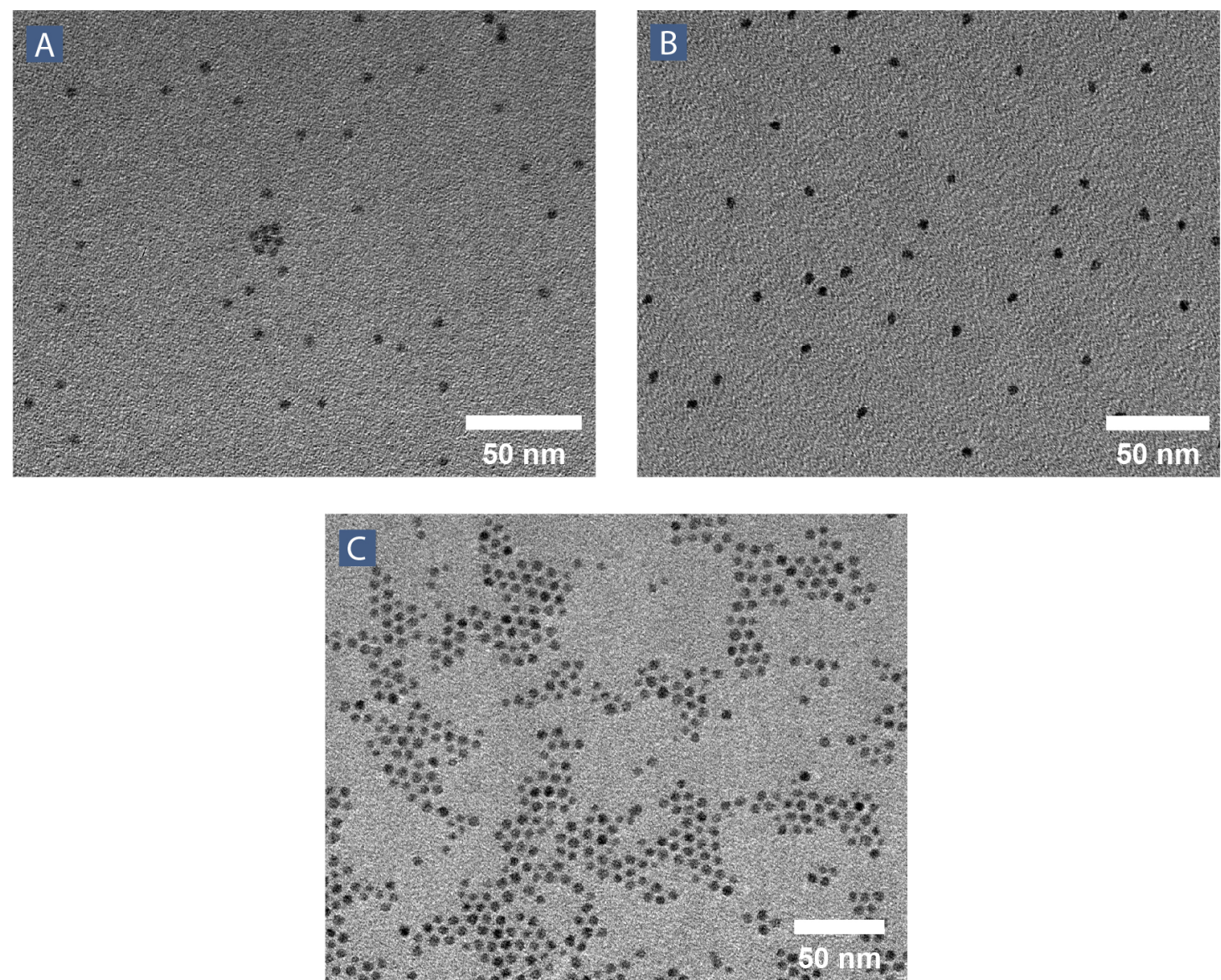

Figure S1 TEM images of CdSe QDs: 580QDs (A, diameter $3.6 \mathrm{~nm} \pm 0.3 \mathrm{~nm}$ ) and 610QDs (B, diameter $4.4 \mathrm{~nm} \pm 0.3 \mathrm{~nm}$ ). TEM image of CdSe/CdS core-shell QDs (C, diameter $5.0 \mathrm{~nm} \pm 0.4 \mathrm{~nm}$ ).

\section{Synthesis of CdSe nanoplatelets based on Ithurria et al. ${ }^{2}$ NPLs emitting at $460 \mathrm{~nm}$ (460NPLs)}

A 1M TOP-Se precursor was prepared by dissolving $157.6 \mathrm{mg}$ elemental selenium in $2 \mathrm{~mL}$ TOP under inert atmosphere. $278 \mathrm{mg}$ cadmium acetate dihydrate, $285 \mu \mathrm{L} \mathrm{OA}$ and $15 \mathrm{~mL}$ ODE was mixed and degassed under vacuum for 1 hour at room temperature. This mixture was heated to $200^{\circ} \mathrm{C}$ under nitrogen atmosphere and $150 \mu \mathrm{L}$ of $1 \mathrm{M}$ TOPSe was injected. After 1 hour at $200^{\circ} \mathrm{C}$, the mixture was cooled down to room temperature. The product was purified twice by addition of $40 \mathrm{~mL}$ methanol/butanol mixture (1:3 ratio) and centrifuged at $2500 \mathrm{rpm}$ ( $700 \mathrm{RCF}$ ) for 10 minutes. NPLs were dispersed in $4 \mathrm{~mL}$ hexane.

\section{NPLs emitting at $510 \mathrm{~nm}$ (510NPLs)}

First, a cadmium myristate precursor was synthesized by dissolving $1.23 \mathrm{~g}$ cadmium nitrate tetrahydrate in $40 \mathrm{ml}$ methanol and $3.13 \mathrm{~g}$ sodium myristate in $250 \mathrm{~mL}$ methanol. The cadmium nitrate solution was added to the sodium myristate solution while stirring. A white precipitate was visible. The precipitate was vacuum filtrated using a Buchner flask and rinsed with $1 \mathrm{~L}$ of methanol. The cadmium myristate was dried overnight under vacuum to remove methanol.

For the synthesis of the nanoplatelets (NPLs) $170 \mathrm{mg}$ cadmium myristate, $15 \mathrm{~mL}$ ODE and $12 \mathrm{mg}$ elemental selenium was heated to $240^{\circ} \mathrm{C}$ under nitrogen atmosphere. At $195^{\circ} \mathrm{C}$, when the mixture turned orange, $40 \mathrm{mg}$ cadmium acetate and $20 \mathrm{mg}$ sodium acetate was added to the reaction mixture. The synthesis was quenched by addition of $15 \mathrm{~mL}$ hexane after $5 \mathrm{~min}$ at $240^{\circ} \mathrm{C}$ (first $5 \mathrm{~mL}$ was added with cation, due to low boiling point of hexane). At $95^{\circ} \mathrm{C} 1 \mathrm{~mL}$ OA was added. NPLs were purified twice by addition of $30 \mathrm{~mL}$ methanol/butanol mixture (1:2) and centrifuged at $3000 \mathrm{rpm}$ ( 1000 RCF). The NPLs were dispersed in $10 \mathrm{~mL}$ hexane. 


\section{Synthesis of CdSe/CdS core-shell NPLs based on Kelestemur et al. ${ }^{3}$ and Rossinelli et al. ${ }^{4}$ $1 \mathrm{ML}$ core-shell NPLs}

A $0.4 \mathrm{M}$ cadmium acetate solution and $0.2 \mathrm{M}$ sulfide solution were prepared under inert atmosphere by dissolving $150.6 \mathrm{mg}$ hydrosulfide hydrate in $10 \mathrm{~mL} \mathrm{~N}$-methylformamide (NMF) and $1066 \mathrm{mg}$ cadmium acetate dihydrate in $9.75 \mathrm{~mL}$ NMF. $1 \mathrm{~mL}$ of the sulfide solution and $1 \mathrm{~mL}$ of the $510 \mathrm{NPLs}$ solution were mixed. In 5 to 10 minutes the NPLs transferred to the NMF phase. The hexane (upper phase) was removed. $1.5 \mathrm{~mL}$ hexane was added, mixed by shaking, and removed. This was repeated once more. The NPLs were further purified by adding $3 \mathrm{~mL}$ toluene and $1 \mathrm{~mL}$ acetonitrile and centrifuged at $3000 \mathrm{rpm}$ (1000 RCF) for $10 \mathrm{~min}$. This was repeated one more time. The product was dispersed in $1 \mathrm{~mL}$ NMF.

The cadmium layer was grown by adding $1 \mathrm{~mL} 0.4 \mathrm{M}$ cadmium acetate solution to the NPLs in NMF. The mixture was stirred for $5 \mathrm{~min}$ at 600 RPM. The NPLs were purified twice with $12 \mathrm{~mL}$ toluene and $4 \mathrm{~mL}$ acetonitrile and centrifuged at $3000 \mathrm{rpm}$ for 10 minutes. The NPLs were dispersed in $1.5 \mathrm{~mL}$ hexane.

\section{$6 \mathrm{ML}$ core-shell NPLs}

$5.75 \mathrm{~g} \mathrm{CdO}$ and $20 \mathrm{~mL}$ acetonitrile were added to a $100 \mathrm{~mL}$ roundbottom flask. The mixture was stirred and cooled with an ice bath. First, $0.7 \mathrm{~mL}$ trifluoroacetic acid was added followed by $6.2 \mathrm{~mL}$ trifluoroacetic anhydride. After 10 minutes the mixture was heated to $50^{\circ} \mathrm{C}$ until a the solution became white. $28.6 \mathrm{~mL} \mathrm{OA}, 180 \mathrm{~mL}$ 2-propanol and $14 \mathrm{~mL}$ triethylamine where mixed and stirred in a $500 \mathrm{~mL}$ Erlenmeyer flask. The cadmium trifluoroacetate solution was added to the OA solution while stirring. The white precipitate was vacuum filtrated using a Buchner flask and rinsed several times with methanol. The product was dried under vacuum overnight.

$140 \mathrm{mg}$ cadmium oleate, $5 \mathrm{~mL}$ ODE and $1.6 \mathrm{~mL}$ 510NPLs were mixed and put under a nitrogen atmosphere. The hexane was evaporated by running a nitrogen flow through a needle over the mixture for 1 hour. $1 \mathrm{~mL}$ oleylamine was added and the mixture was heated to $300^{\circ} \mathrm{C}$. When a temperature of $180^{\circ} \mathrm{C}$ was reached, $7 \mathrm{~mL} / \mathrm{L}$ 1-octanethiol in ODE was added with a rate 0 f $3 \mathrm{~mL} / \mathrm{h}$ using a syringe pump. After 75 minutes the reaction mixture was cooled down to room temperature using an air flow. $5 \mathrm{~mL}$ hexane was added and the mixture was centrifuged at $3000 \mathrm{rpm}$ ( 1000 RCF) for $10 \mathrm{~min}$. The NPLs were dispersed in $5 \mathrm{~mL}$ hexane and $100 \mu \mathrm{L}$ oleylamine was added. The mixture was centrifuged twice at $3000 \mathrm{rpm}$ for $10 \mathrm{~min}$. After discarding the supernatant, $5 \mathrm{~mL}$ hexane was added in between the centrifuge cycles. The final product was dispersed in $5 \mathrm{~mL}$ hexane.

The thickness of the CdS shell is estimated to be 6 monolayers (ML), based on the position of the PL spectrum at room temperature $(658 \mathrm{~nm})$ compared to the spectra of $4 \mathrm{ML}$ thick shell $(\sim 650 \mathrm{~nm})$ and $7 \mathrm{ML}$ thick shell $(\sim 662 \mathrm{~nm}) .^{5}$

TEM image of core and core-shell NPLs of the synthesis described above are shown in figure S2. 

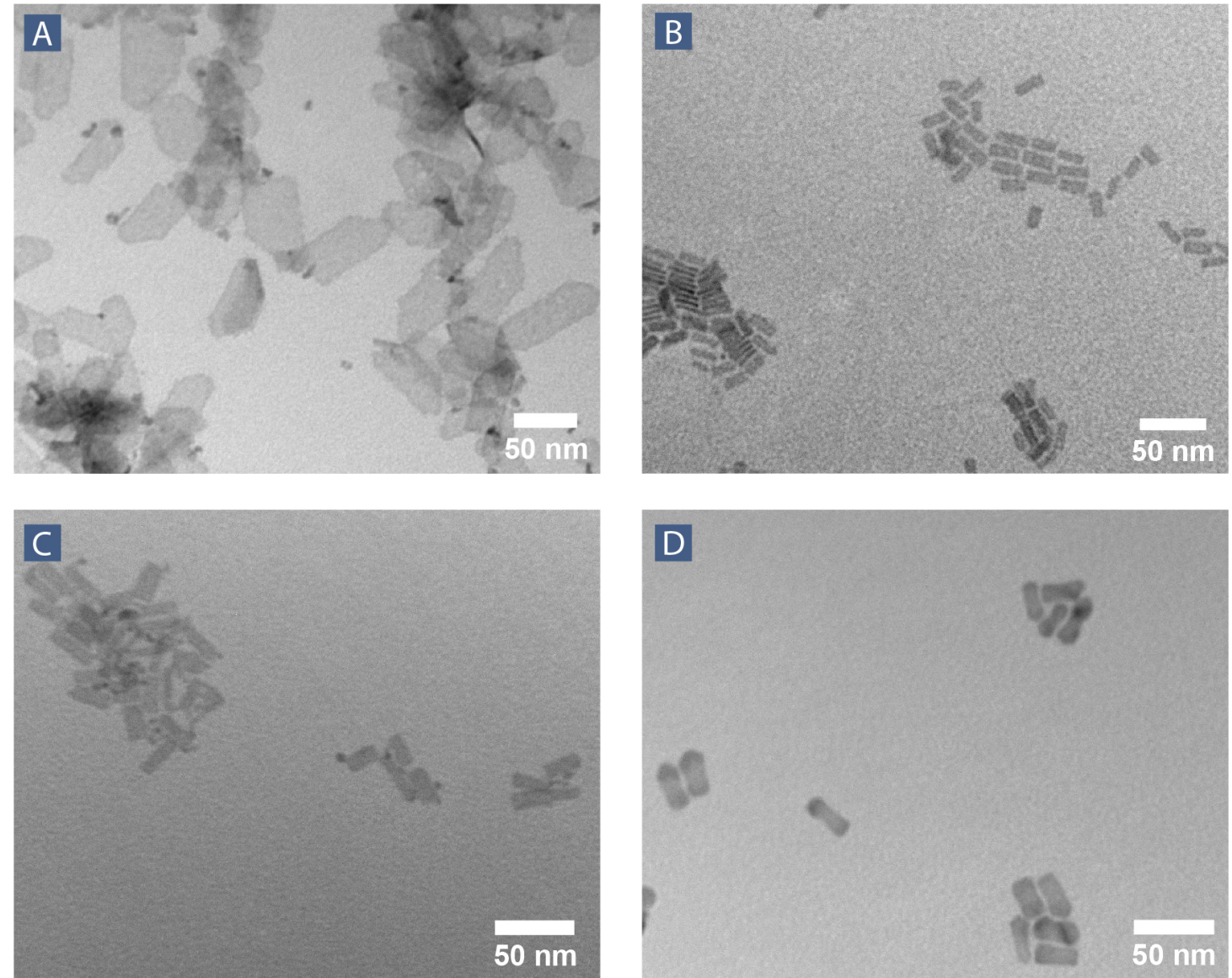

Figure S2 TEM images of CdSe NPLs of 3.5 ML (A, 460NPLs) with large lateral dimensions (length: 76 $\mathrm{nm} \pm 18 \mathrm{~nm}$, width: $34 \mathrm{~nm} \pm 10 \mathrm{~nm}$ ) and NPLs of $4.5 \mathrm{ML}$ (B, 510NPLs) with small lateral dimensions (length: $19 \mathrm{~nm} \pm 2.1 \mathrm{~nm}$, width: $7.1 \mathrm{~nm} \pm 1.3 \mathrm{~nm}$ ). In C and D TEM images of core-shell NPLs with 1 ML CdS (length: $22 \mathrm{~nm} \pm 4.2 \mathrm{~nm}$, width: $7.7 \mathrm{~nm} \pm 1.3 \mathrm{~nm}$ ) and $6 \mathrm{ML}$ CdS (length: $24 \mathrm{~nm} \pm 3.5 \mathrm{~nm}$, width: $9.7 \mathrm{~nm} \pm 1.4 \mathrm{~nm}$ ) are shown respectively.

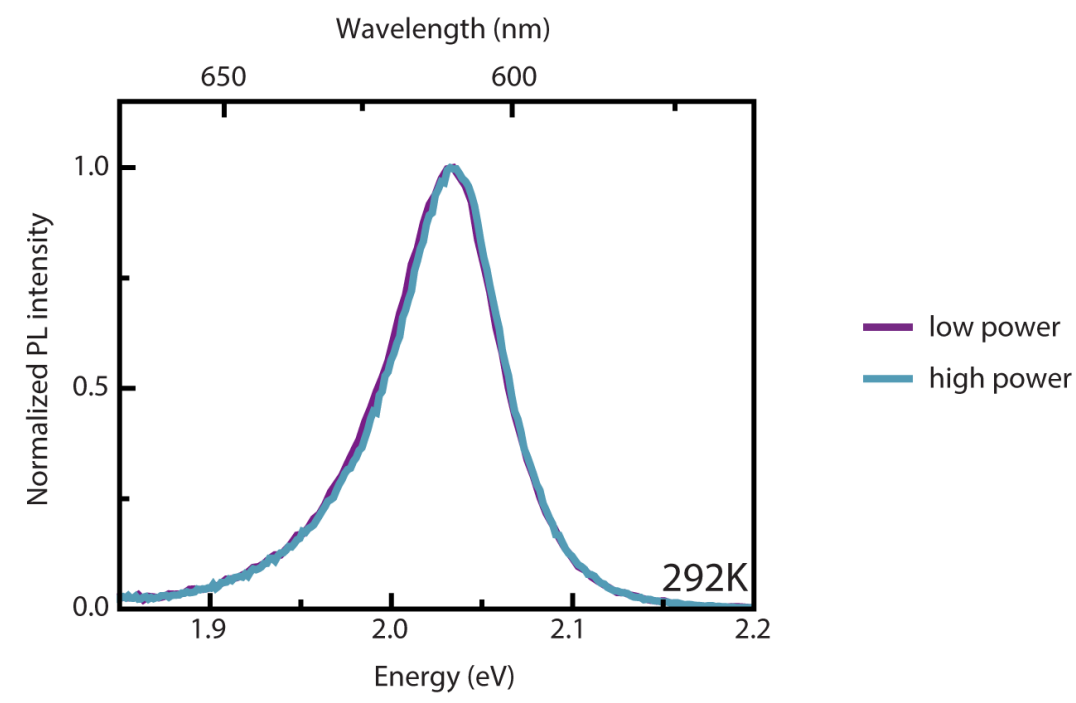

Figure S3 Comparison PL spectra with a typical excitation power used during measurements (upper limit $\sim 100 \mathrm{~mW} / \mathrm{cm}^{2}$, violet) and a spectrum recorded at twice the excitation power (blue). No change in the line width was observed. 

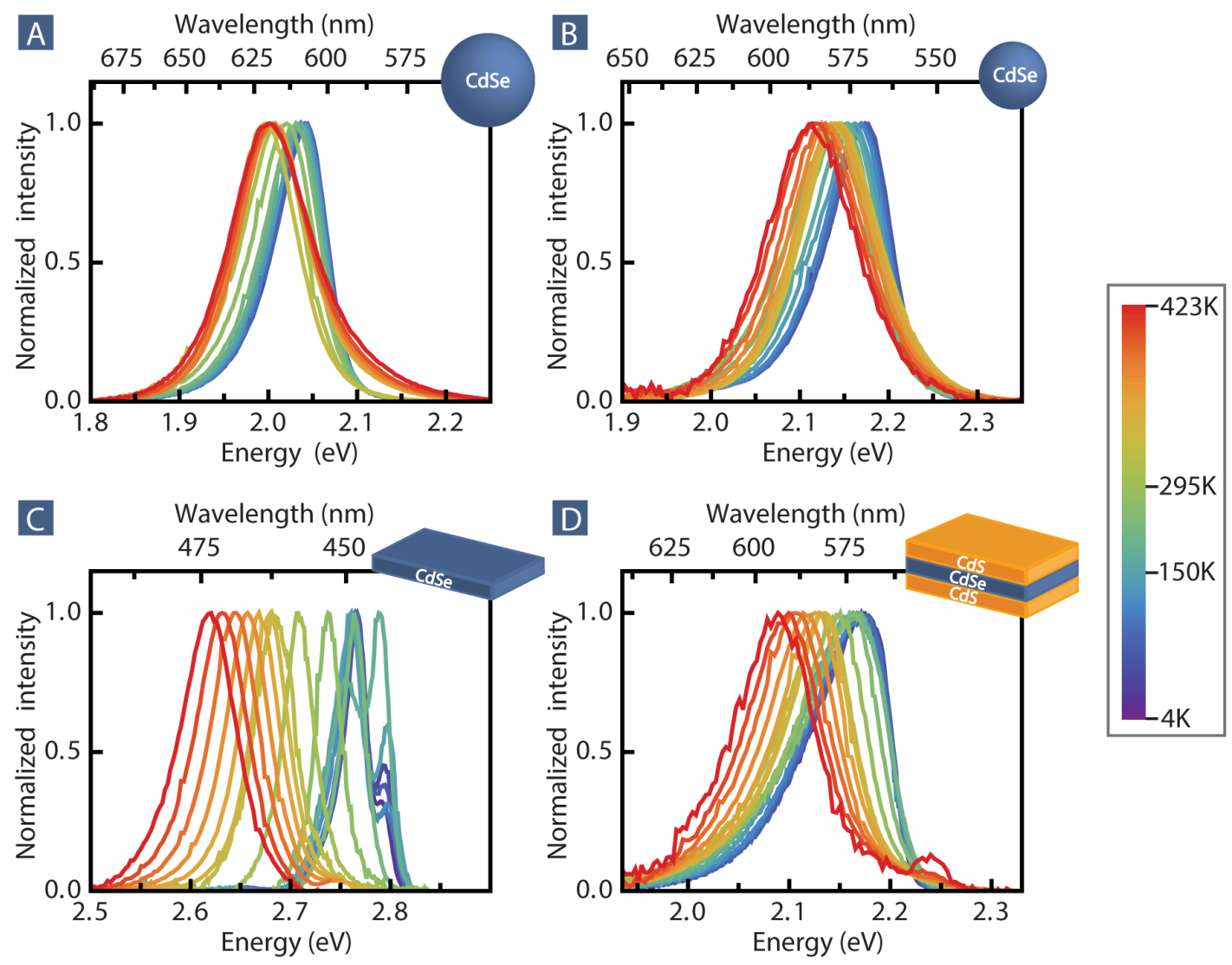

Figure S4 Normalized temperature dependent spectra of A) 610QDs, B) 580QDs, C) 460NPLs and D) $1 \mathrm{ML}$ core-shell NPLs. Temperature ranges from $4 \mathrm{~K}$ (violet) to $423 \mathrm{~K}$ (red). At a temperature of $150 \mathrm{~K}$ and lower a second peak is observed in C and a more asymmetric PL spectrum in D.
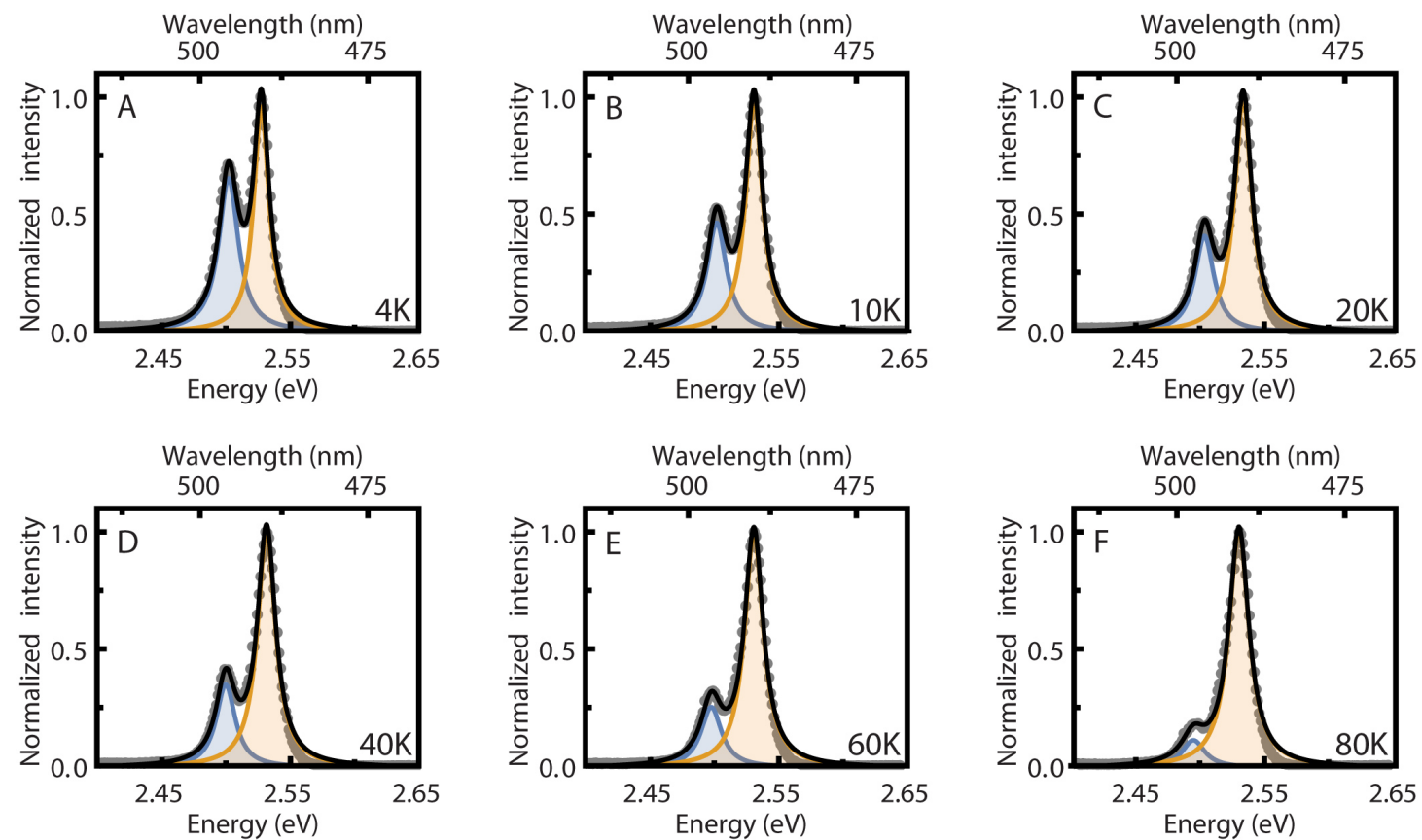

Figure S5 Data PL spectra 510NPLs at low temperatures (gray dots). Splitting of the PL spectra can be observed at low temperatures. Intensity of peak at lower energy increases with decreasing temperature. Data is fitted with sum of two Lorentzian functions (black). Contributions of both Lorentzian functions are shown in blue and orange. The wings of the Lorentzian fit deviates from the data. This results in an incorrect determination of the FWHM when the intensity of the low energy peak is high. 


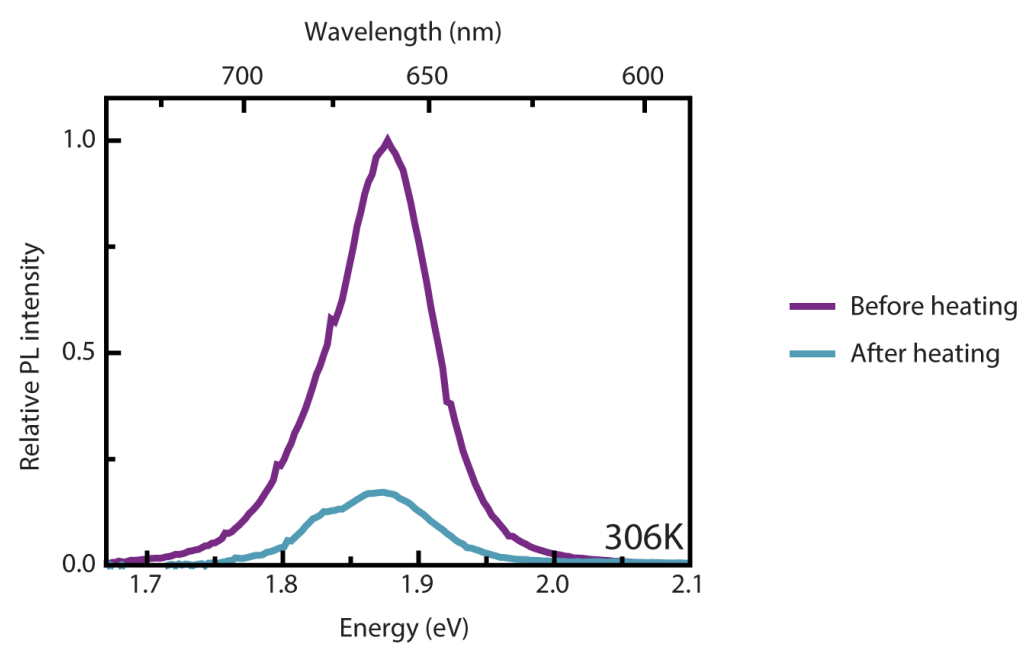

Figure S6 PL spectra of 6ML core-shell NPLs at $306 \mathrm{~K}$ before and after heating to $423 \mathrm{~K}$. PL is irreversible quenched due to heating at high temperatures.

\section{References}

(1) Li, J. J.; Wang, Y. A.; Guo, W.; Keay, J. C.; Mishima, T. D.; Johnson, M. B.; Peng, X. Large-Scale Synthesis of Nearly Monodisperse Cdse/Cds Core/Shell Nanocrystals Using Air-Stable Reagents Via Successive Ion Layer Adsorption and Reaction. J. Am. Chem. Soc. 2003, 125, 12567-12575.

(2) Ithurria, S.; Bousquet, G.; Dubertret, B. Continuous Transition from 3d to 1d Confinement Observed During the Formation of Cdse Nanoplatelets. J. Am. Chem. Soc. 2011, 133, 3070-3077.

(3) Kelestemur, Y.; Guzelturk, B.; Erdem, O.; Olutas, M.; Gungor, K.; Demir, H. V. Platelet-in-Box Colloidal Quantum Wells: Cdse/Cds@Cds Core/Crown@Shell Heteronanoplatelets. Adv. Funct. Mater. 2016, 26, 3570-3579.

(4) Rossinelli, A. A.; Riedinger, A.; Marques-Gallego, P.; Knusel, P. N.; Antolinez, F. V.; Norris, D. J. High-Temperature Growth of Thick-Shell Cdse/Cds Core/Shell Nanoplatelets. Chem. Commun. 2017, 53, 9938-9941.

(5) Ithurria, S.; Talapin, D. V. Colloidal Atomic Layer Deposition (C-Ald) Using Self-Limiting Reactions at Nanocrystal Surface Coupled to Phase Transfer between Polar and Nonpolar Media. J. Am. Chem. Soc. 2012, 134, 18585-18590. 